\title{
INTERDISCIPLINARIDADE, A PARTIR DE JOGOS DIDÁTICOS PEDAGÓGICOS, EM UMA PERSPECTIVA INCLUSIVA.
}

\author{
Janine Cecília Gonçalves Peixotol \\ ESEBA-UFU ${ }^{26}$ \\ janinecgp@gmail.com
}

Resumo: Os jogos pedagógicos para o Ensino Fundamental são amplamente estudados e divulgados em pesquisas de muitos educadores. Sendo assim, de que modo os jogos didáticos-pedagógicos interferem nos processos de aprendizagem e nas relações entre os participantes? Como as inter-relações entre as crianças podem se tornar menos competitivas e mais colaborativas, contribuindo para uma sociedade mais humanizada, inclusiva? Por um lado, os jogos ampliam a capacidade do raciocínio lógico no desenvolvimento infantil, por outro pode se tornar uma concorrência nas questões de relações humanas e cooperativas dentro do espaço da sala de aula. Assim, os jogos podem ter características facilitadoras no que tange à interação entre as pessoas, nas relações humanas, nos conhecimentos, saberes e experiências, características relacionadas à uma perspectiva sócio interacionista, segundo Vygotsky. Consideramos que os jogos pedagógicos e didáticos, promovem a construção do pensamento, auxilia a criança no desenvolvimento linguístico, na escrita e no raciocínio lógico-matemático. Jogar, em sala de aula, amplia a aprendizagem, auxilia o professor no processo educativo, favorece as relações interpessoais: professor/aluno - aluno/aluno - professor/aluno/contexto social, e promove a inclusão pois todos auxiliam todos, independentemente das necessidades de cada um. Esse projeto, já em andamento, tem a intenção de aprofundar os estudos sobre os jogos didáticos pedagógicos, as maneiras e as possibilidades de aplicações em sala de aula, utilizando estratégias interdisciplinares de ensino, que permita, de forma lúdica e interativa, aprendizagens significativas. Articular diferentes disciplinas, contextualizar os conteúdos de forma interdisciplinar e favorecer um saber ampliado dos conhecimentos linguísticos, matemáticos, históricos, geográficos e científicos, alinhados ao planejamento do ano/série, são os principais objetivos deste projeto, desenvolvido na Escola de Educação Básica/Eseba, com alunos do $2^{\circ}$ ano do Ensino Fundamental. Deste modo, o projeto em andamento desenvolve ações de planejamento e organização dos jogos, aplicação e análise pedagógica, com a orientação da professora e autora do projeto e auxílio da bolsista do PROGRAD (Programa de Bolsas de Graduação). Esse projeto demonstra como a partir dos jogos

\footnotetext{
${ }^{26}$ Janine Cecília Gonçalves Peixoto- Pedagoga desde 2006 pelo Centro Universitário do Triângulo (UNITRI), com especialização em Atendimento Educacional Especializado (UNIANDRADE) e Docência para Diversidade na Educação Básica(UFU). Professora do $2^{\circ}$ ano do Ensino Fundamental durante o período de 2016/2017, na Escola de Educação Básica da Universidade Federal de Uberlândia/ ESEBA/UFU. Link currículo lattes: http://lattes.cnpq.br/0644353498340485
} 
obtemos informações significativas no que se refere às interações sociais, aprendizagem, trabalho interdisciplinar e registro pedagógico, contextualizam o conhecimento às crianças e permitem que o processo de inclusão aconteça.

\section{Introdução}

Alguns jogos didáticos-pedagógicos são criados, elaborados e aplicados com a intenção de promover o ensino e aprendizagem de modo mais lúdico e significativo. Sendo assim, os docentes procuram experimentar diferentes jogos para alcançar esse significado mais contextualizado de um determinado conteúdo a ser introduzido, aprofundado e consolidado nos três anos iniciais do ensino fundamental, haja vista a intensificação das políticas públicas brasileiras em relação à aprendizagem em uma idade determinada (Brasil, 2012).

Murcia (2005, p.9) nos conta um pouco sobre a historicidade dos jogos:

O jogo é um fenômeno antropológico que se deve considerar no estudo do ser humano. É uma constante em todas as civilizações, esteve sempre unido à cultura dos povos, a sua história, ao mágico, ao sagrado, ao amor, a arte, a língua, a literatura, aos costumes, a guerra. O jogo serviu de vínculo entre povos, é facilitador da comunicação entre seres humanos.

De acordo com essa premissa, o jogo pode ter características facilitadoras no que tange à interação entre as pessoas, nas relações humanas, nos conhecimentos, saberes e experiências, promovendo assim que a aprendizagem aconteça em uma perspectiva sócio interacionista, segundo Vygotsky. De acordo com Oliveira (2004):

A aprendizagem acontece por meio da internalização, a partir de um processo anterior, de troca, que possui uma dimensão coletiva. Segundo Vygotsky, a aprendizagem deflagra vários processos internos de desenvolvimento mental, que tomam corpo somente quando o sujeito interage com objetos e sujeitos em cooperação. Uma vez internalizados, esses processos tornam-se parte das aquisições do desenvolvimento.

Sendo assim, essas atividades interativas e os jogos usados como estratégias, promovem a inclusão de todos os estudantes no desenvolvimento do seu aprendizado, pois permite a internalização dos processos do aprender na interação com outros sujeitos. 
Podemos considerar que, os jogos pedagógicos e didáticos, promovem a construção do pensamento, auxilia o estudante nos processos do seu desenvolvimento linguístico, sua escrita e seu raciocínio lógico-matemático. Jogar em sala de aula, também amplia a aprendizagem para outras esferas pois, auxilia o professor no processo educacional, favorece as relações interpessoais, professor/estudante - estudante/estudante - professor/estudante/meio e possibilita a inclusão privilegiando o "saber-fazer" e o "aprender-ensinar" de todos e de cada um.

O jogo por seu carácter cultural influencia todos os grupos sociais, por isso a facilidade em incluir todos os estudantes nas propostas. As propostas e estratégias apresentadas aos estudantes, os tipos de jogos e o vínculo entre os participantes são diferentes, mas atingem a todos, pois considera-se que todos podem aprender. As práticas que envolvem os jogos servem de vínculo, facilita a comunicação e permite a apropriação de conhecimentos e experiências únicas.

Diante dessas reflexões, percebemos que os docentes procuram elaborar estratégias e jogos que permitem desenvolver o saber dos estudantes, em especial os profissionais que iniciam seus trabalhos junto à educação básica, assim que concluem os cursos de graduação. É de suma importância conhecer, compreender, organizar e articular os jogos didáticos pedagógicos com fins cooperativos e que consigam articular aprendizados significativos junto aos discentes. Esse projeto, ainda em andamento, intenciona aprofundar os estudos sobre os jogos didáticos pedagógicos, as maneiras e as possibilidades de aplicações em sala de aula, utilizando estratégias interdisciplinares de ensino, que promova de forma lúdica e interativa aprendizagens significativas.

O professor alfabetizador, não ensina apenas a leitura e escrita. A alfabetização acontece com todos e quaisquer componentes curriculares, aprende-se também com as relações. Por isso, o professor, ao refletir sobre práticas em sala de aula e ousar estratégias diferenciadas de articulação entre as diferentes disciplinas, contextualizando os conteúdos de modo interdisciplinar, favorece um saber ampliado dos conhecimentos linguísticos, matemáticos, históricos, geográficos e científicos, enquanto componentes curriculares.

Nesse sentido, os jogos didáticos pedagógicos favorecem essa interlocução entre as disciplinas, viabiliza uma articulação entre os saberes e amplia os 
conhecimentos. Para que o professor alfabetizador consiga realizar esse trabalho, ele mesmo precisa compreender o conhecimento de modo contextualizado, necessita ampliar sua visão e estabelecer diretrizes na intenção de seu trabalho em uma perspectiva de aprender e ensinar, como nos diz Paulo Freire (1997): "Quem ensina aprende ao ensinar e quem aprende ensina ao aprender".

A aplicação dos jogos durante o projeto promove a ludicidade e aprendizagem de diferentes conteúdos trabalhados na alfabetização, por meio de propostas com jogos didáticos pedagógicos e leitura, que estimulam a capacidade de interpretação e raciocínio dos estudantes.

Ao jogos promovem o desenvolvimento da capacidade de resolução de problemas, o que amplia a capacidade cognitiva tanto para o raciocínio quanto para interpretação, envolvendo a leitura, escrita, cálculos entre outros saberes necessários. Segundo Smole e Diniz (2012, p. 22):

......os alunos resolvem muitos problemas adquirem novos
conhecimentos e habilidades. Investigar, decidir, levantar e
checar hipóteses são algumas das habilidades de raciocínio
lógica solicitadas a cada jogada, pois quando se modificam as
condições do jogo, o jogador tem eu analisar novamente toda a
situação e decidir o que fazer...

A leitura amplia o repertório de vocabulário, permite a criança desenvolver a criatividade, a imaginação, a compreensão dos textos lidos e a capacidade de interagir com o meio de forma mais ampliada. Segundo Coelho (2000. p.16), a escola é um espaço privilegiado para o encontro entre a criança e os livros, sendo assim, para a formação do indivíduo é necessário alguns estímulos como:

\begin{abstract}
..... " exercício da mente; a percepção real em múltiplas significações; a consciência do eu em relação com o outro; a leitura de mundo em seus vários níveis e principalmente.... estudo e conhecimento da língua, da expressão verbal significativa e consciente- condição sine qua non para a plena realidade do ser.
\end{abstract}

Nesse aspecto, podemos identificar que o papel da escola e do professor, é o incentivo diário ao desafio. Desafio em ler, compreender, raciocinar, investigar, checar, prever, articular e podemos considerar que todas essas habilidades são proporcionadas a partir de estratégias de trabalho interdisciplinares. Deste modo 
o aluno, desafiado em seu contexto torna-se mais crítico, reflexivo, hábil em tomada de decisões.

Podemos ousar dizer que as atividades interdisciplinares por meio de jogos didáticos pedagógicos são ferramentas que auxiliam na organização do pensamento, já que esses, para a alfabetização, exigem dos estudantes processos cognitivos como identificação, seleção, classificação, comparação, organização, categorização, elaboração e estruturação. Todos esses aspectos do raciocínio cognitivo, auxiliam a alfabetização. Por isso, necessita-se organizar estratégias claras que de fato promovam aprendizado significativo com ludicidade e prazer.

É essencial que os professores alfabetizadores na tomada de decisões em relação aos jogos didáticos pedagógicos, planejem suas ações de modo a contribuir para a qualidade do ensino nos anos iniciais, segundo Ausubel (1980). Para esse autor, o estudante é capaz de compreender e aprender melhor desde que a informação recebida faça algum sentido, seja pela ludicidade ou pela necessidade do saber para um fim específico, dentro do processo de aquisição do conhecimento.

As estratégias utilizadas na aplicação de atividades interdisciplinares e jogos didáticos pedagógicos devem interagir e articular conceitos relevantes notados nas possibilidades cognitivas do estudante (Moreira, 2001). Sendo assim, o professor propõe aos estudantes, jogos que possam articular e possibilitar um trabalho interdisciplinar que também contempla temas ligados ao seu dia a dia, valorizando o aporte cultural que os estudantes trazem de seu ambiente, suas manifestações linguísticas e práticas coletivas com seus familiares. E do mesmo modo poderão levar para a casa, junto à família os significativos aprendizados que obter na escola.

De acordo com Brasil (2014, p. 05),

Trabalhado de forma adequada, além dos conceitos, o jogo possibilita aos alunos desenvolver a capacidade de organização, análise, reflexão e argumentação, uma série de atitudes como: aprender a ganhar e a lidar com o perder, aprender a trabalhar em equipe, respeitar regras, entre outras. No entanto, para que o ato de jogar na sala de aula se caracterize como uma metodologia que favoreça a aprendizagem, o papel do professor é essencial. Sem a intencionalidade pedagógica do professor, corre-se o risco de se utilizar o jogo sem explorar seus aspectos educativos, perdendo grande parte de sua potencialidade.

Assim, as atividades interdisciplinares a partir dos jogos didáticos pedagógicos, envolvendo diferentes componentes curriculares, norteiam o trabalho em salas de 
aula nas atividades de análise, interpretação e produção de saberes favorecendo o desenvolvimento de capacidades linguísticas e lógicas dos alunos. Kamii (2007) considera a importância do ensino da escrita, leitura e a matemática:

As crianças não podem estar alertas e ser curiosas sem se interessar por objetos culturais do seu meio ambiente, tais como...sinais de rua e rótulos de caixas e latas. Crianças alertas se interessam em saber quantas crianças estão presentes ou ausentes, ... na lista dos nomes, dos aniversariantes ... (Kamii, 2007, p. 17)

Ao concordar com Kamii(2007), estabelecemos que a escrita, leitura e matemática são aprendizagens importantes que aliadas à conhecimentos culturais e significativamente sociais dos estudantes, promovem ainda mais os saberes necessários para o desenvolvimento intelectual dos mesmos.

Partindo dessa perspectiva, sintetizamos abaixo um quadro que exemplifica e articula as possibilidades de estratégia interdisciplinar entre conteúdos e componentes curriculares, os quais podem ser trabalhados com jogos didáticos pedagógicos adequados aos alunos do $2^{\circ}$ ano do Ensino Fundamental.

\begin{tabular}{|c|c|c|}
\hline $\begin{array}{c}\text { COMPONENTE } \\
\text { CURRICULAR }\end{array}$ & CONTEÚDOS & $\begin{array}{c}\text { EXEMPLOS DE JOGOS PEDAGÓGICOS E } \\
\text { ATIVIDADES INTERDICIPLINARES A PARTIR DOS } \\
\text { JOGOS }\end{array}$ \\
\hline $\begin{array}{c}\text { Ciências Naturais e } \\
\text { Humanas (história } \\
\text { e geografia) }\end{array}$ & Corpo Humano & $\begin{array}{l}\text { - Quebra cabeça das partes do corpo. } \\
\text { - Jogos da memória sobre os } 5 \text { sentidos } \\
\text { - Dominó de hábitos de higiene. } \\
\text { - Jogo Cara a Cara (Características físicas) e } \\
\text { composição familiar. } \\
\text { - Entre outros }\end{array}$ \\
\hline Matemática & Corpo Humano & $\begin{array}{l}\text { - Quantos palmos podemos usar para medir? } \\
\text { - O que é a polegada? } \\
\text { - Contagem com o uso do corpo. (dedos das } \\
\text { mãos/pés) } \\
\text { - Entre outras }\end{array}$ \\
\hline Língua Portuguesa & Corpo Humano & $\begin{array}{l}\text { - Escrita de um relato sobre os jogos trabalhados } \\
\text { - Ditado com os nomes que aparecem no } \\
\text { dominó da higiene } \\
\text { - Leitura das regras dos jogos (Gênero Textual) } \\
\text { - Bilhete, convite para o colega. } \\
\text { - Leitura e escrita de textos } \\
\text { - Entre outros }\end{array}$ \\
\hline
\end{tabular}

Um ponto importante que é preciso esclarecer é que os jogos didáticos pedagógicos, que foram aplicados até o momento aos estudantes, precisam estar 
alinhados ao planejamento do ano/série e seguindo uma sequência e ordem de prioridades. No entanto, caso o interesse dos estudantes e os questionamentos se estendam nada impede de que o trabalho seja ampliado, mas sempre articulando com o conteúdo programado, junto aos documentos oficiais da escola e do MEC 27 , para o $2^{\circ}$ ano do Ensino Fundamental.

Sabemos que há uma imprevisibilidade nas ações planejadas, visto que o cotidiano da sala de aula e o espaço/tempo ao qual se destinam as atividades interdisciplinares por meio dos jogos didáticos pedagógicos, podem sofrer interferências. Nesse sentido, esse projeto tem um caráter flexível, podendo ser ajustado conforme a necessidade do programa e diante de situações não prevista. Isso também permite que seja avaliado e reavaliado constantemente durante sua execução para novas adaptações e reorganizações.

Consideramos que esse projeto até o presente momento, tem favorecido e contribui significativamente com o desenvolvimento de aspectos como: conceitos, capacidade de organização nas crianças, análises, reflexão, argumentação, além de aprender atitudes como: ganhar, lidar com a perda, aprender a cooperar, trabalhar em equipe, respeitar regras, apreender saberes de diferentes disciplinas partindo de um trabalho com jogos didáticos pedagógicos.

\section{Metodologia}

Este projeto é desenvolvido a partir de aplicação de jogos didáticos pedagógicos, além de estratégias de trabalho e organização de práticas pedagógicas que relacionam os conteúdos do ano/série de maneira interdisciplinar, que favorecem de forma lúdica e envolvente o aprendizado dos estudantes. Para o desenrolar do trabalho, iniciamos por selecionar, os jogos e textos específicos que contextualizem o conteúdo relacionado ao trimestre do ano/série citado. Deste modo, o trabalho é desenvolvido, organizado a partir de contextos relacionados, tendo como referência e articulador dos saberes os jogos elaborados e textos previamente selecionados. $O$ professor coordenador do projeto orienta o estudante da Universidade por meio do Prograd, na difícil tarefa de articular os conteúdos afins. Juntos tem o papel crucial de mediar o saber, buscando as conexões com os diferentes componentes curriculares

${ }^{27}$ MEC- Ministério da Educação e Cultura. 
e os conhecimentos para então organizar os jogos que serão aplicados em sala de aula.

Entre as atividades propostas no decorrer do ano deverão estar presentes, aquelas que instigam prazer pelos jogos, as interações sociais, e atividades que permeiam os conteúdos disciplinares, levando em conta as diferenças de todos e cada um, em uma perspectiva inclusiva de educação.

Para exemplificar foi aplicado um jogo com o nome Tire ou junte, em que incluíam atividades relacionadas ao componente curricular: Matemática, no conteúdo de operações de adição e subtração. No entanto o jogo vai além na perspectiva do projeto. A leitura das regras do jogo foi trabalhado como introdução ao conteúdo gêneros textuais, oralidade na produção de texto coletiva e texto de opinião com a produção de texto individual contemplando o componente curricular: Língua Portuguesa.

Outro exemplo que podemos citar é o trabalho relacionado ao texto: Só um Minutinho de Yuyi Morales com tradução de Ana Maria Machado. No quadro abaixo relaciona-se as atividades e os jogos trabalhados com suas características interdisciplinares:

\begin{tabular}{|c|c|c|}
\hline $\begin{array}{c}\text { COMPONENTE } \\
\text { CURRICULAR }\end{array}$ & CONTEÚDOS & ATIVIDADES INTERDICIPLINARES APLICADAS \\
\hline $\begin{array}{c}\text { Ciências Naturais e } \\
\text { Humanas (história } \\
\text { e geografia) }\end{array}$ & $\begin{array}{l}\text { Família } \\
\text { Fases da vida } \\
\text { humana }\end{array}$ & $\begin{array}{l}\text { - Pessoas da família da vovó Carocha } \\
\text { (personagem) } \\
\text { - Aniversário da personagem } \\
\text { - Fases da vida (nascer, crescer, reproduzir, } \\
\text { morrer) } \\
\text { - Jogo da memória das fases da vida. }\end{array}$ \\
\hline Matemática & $\begin{array}{l}\text { Sistema de } \\
\text { medidas tempo } \\
\text { e capacidade }\end{array}$ & $\begin{array}{l}\text { - Marcação de tempo (hora, minutos) } \\
\text { - Jogos do relógio } \\
\text { - Utilização dos instrumentos de medida de } \\
\text { capacidade para fazer as receitas descritas na } \\
\text { história } \\
\text { - Jogo de trilha sobre o Sistema de Medidas. }\end{array}$ \\
\hline Língua Portuguesa & $\begin{array}{l}\text { Leitura } \\
\text { Oralidade } \\
\text { Produção de } \\
\text { texto } \\
\text { Interpretação } \\
\text { Gêneros } \\
\text { textuais }\end{array}$ & $\begin{array}{l}\text { - Leitura do texto } \\
\text { - Interpretação da história } \\
\text { - Discussão oral sobre o tempo e o que o } \\
\text { personagem estava fazendo na casa da vovó } \\
\text { - Escrita de um relato a partir da leitura } \\
\text { - Pesquisa de significados de palavras que } \\
\text { - } \text { aparecem no texto } \\
\text { - Bilhete e convite, que aparecem na história }\end{array}$ \\
\hline
\end{tabular}




\begin{tabular}{|l|l|l|}
\hline & & $\begin{array}{l}\text { Entre outros } \\
\text { Jogo dominó de palavras e seus significados, a } \\
\text { partir de palavras da história. }\end{array}$ \\
\hline
\end{tabular}

\section{Considerações finais}

A avaliação nesse projeto tem caráter formativo, pois o professor/orientador acompanha todos os dias, a todo momento, a aprendizagem ou não aprendizagem dos estudantes, observa como estão participando das atividades propostas: jogos didáticos pedagógicos e leitura em sala de aula; como interagem entre si nas propostas e posteriormente como compreendem a articulação e contextualização dos conteúdos por meio do trabalho interdisciplinar.

Para tanto, é necessário fazer registros coletivos e individuais dos trabalhos desenvolvidos, avaliar seus avanços e confirmar o domínio das habilidades esperadas e elencadas no objetivo deste projeto.

O professor orientador e o bolsista (estudante da graduação) analisam no decorrer do trabalho se os estudantes conseguem interagir uns com os outros, se articulam os saberes, se estabelecem conexões entre os conhecimentos e se percebem que o trabalho está interligado.

É importante que o professor se prepare para intervir e mediar as atividades ao conduzir os estudantes nas propostas a fim de avançar na aprendizagem. O bolsista participa do planejamento, organização, confecção de materiais, efetivação da proposta de trabalho, e na aplicação de todas as propostas em sala de aula, além de analisar junto ao professor/orientador questões referentes à avaliação contínua, processual e sistemática com observação e registro das proposições do projeto, bem como escrever relatos simples sobre as aulas e as observações durante a execução das atividades deste projeto.

As atividades realizadas pelos estudantes, foi divulgada em alguns eventos acadêmicos, como o SICEA(2016) Il Seminário Inte-Regional Sul-Sudeste de Institutos, Escolas e Colégios de Aplicação, no Rio de Janeiro/RJ, apresentando resultados incompletos em 2016 e em 2017 no evento: I Seminário Regional de Educação Básica, em Uberlândia /MG em 27 de outubro, no Grupo de Trabalho nº 17: Jogos Pedagógicos: estratégias para atividades interdisciplinares, em que foi apresentado e exposto os trabalhos e os jogos já aplicados nos anos de 2016 e 2017. 


\section{Referências Bibliográficas}

AUSUBEL, D.P.; NOVAK, J.D. e HANESIAN, H. Psicologia educacional. Rio de Janeiro, Interamericana. Tradução para português, de Eva Nick et al., da segunda edição de Educational psychology: a cognitive view, 1980

BRASIL. Pacto Nacional pela Alfabetização na Idade Certa: Formação do Professor Alfabetizador. Caderno de Apresentação. Ministério da Educação, Secretaria de Educação Básica, Diretoria de Apoio à Gestão Educacional. Brasília: MEC, SEB, 2012

BRASIL. Pacto Nacional pela Alfabetização na Idade Certa: Formação do Professor Alfabetizador. Planejando a Alfabetização e Dialogando com diferentes áreas do conhecimento. : ano 2, unidade 6/ Ministério da Educação, Secretaria de Educação Básica, Diretoria de Apoio à Gestão Educacional. Brasília: MEC, SEB, 2012

BRASIL. Pacto Nacional pela Alfabetização na Idade Certa: Formação do Professor Alfabetizador. A organização do planejamento e da rotina no ciclo de alfabetização na perspectiva do letramento: ano 2, unidade 2. Ministério da Educação, Secretaria de Educação Básica, Diretoria de Apoio à Gestão Educacional. Brasília: MEC, SEB, 2012

BRASIL. Pacto Nacional pela Alfabetização na Idade Certa: Formação do Professor Alfabetizador. Jogos na Alfabetização Matemática. Ministério da Educação, Secretaria de Educação Básica, Diretoria de Apoio à Gestão Educacional. Brasília: MEC, SEB, 2014

BRASIL. Pacto Nacional pela Alfabetização na Idade Certa: Formação do Professor Alfabetizador. Saberes Matemáticos e outros Saberes. Ministério da Educação, Secretaria de Educação Básica, Diretoria de Apoio à Gestão Educacional. Brasília: MEC, SEB, 2014.

COELHO, Nelly Novaes. Literatura infantil: teoria, análise, didática. $1^{\text {a }}$ ed. São Paulo: Moderna 2000.

KAMII, Constance. Jogos em grupo na educação infantil: implicações da teoria de Piaget./Constance Kamii e Rheta Devries; tradução Marina Célia Dias Carrasqueria; prefácio de Jean Piaget. São Paulo: Trajetória Cultural,1991.

MEIER, Marcos. Mediação da Aprendizagem: contribuições de Feuerstein e de Vygostsky/Marcos Meier, Sandra Garcia. -Curitiba: Edição do autor,2007.

MOREIRA, M.A. e MASINI, Elcie F. Salzano. Aprendizagem significativa: a teoria de David Ausubel. São Paulo: Centauro, 2001.

MURCIA, JUAN ANTONIO MORENO (ORG). Aprendizagem Através Do Jogo. PORTO ALEGRE: ARTMED, 2005.

Sites:

https://blogdaformacao.wordpress.com/2007/11/16/quem-ensina-aprende-aoensinar-e-quem-aprende-ensina-ao-aprender/- acesso em 13/07/2016. 
http://www.abed.org.br/congresso2004/por/htm/171-TC-D4.htm - O processo de aprendizagem em uma perspectiva sócio - interacionista ... Ensinar é necessário, avaliar é possível -Abril/2004 acesso em 03/11/2017 